\title{
Patient-reported outcomes in thoracic surgery-opportunities and current challenges
}

\author{
Peter J. Kneuertz ${ }^{1,2}$, Ann Scheck McAlearney ${ }^{2,3}$, Susan D. Moffatt-Bruce ${ }^{1,2}$ \\ ${ }^{1}$ Thoracic Surgery Division, Department of Surgery, The Ohio State University Wexner Medical Center, Columbus, OH, USA; ${ }^{2}$ Center for the \\ Advancement of Team Science, Analytics, and Systems Thinking (CATALYST) in Health Services and Implementation Science Research, The Ohio \\ State University College of Medicine, Columbus, OH, USA; ${ }^{3}$ Department of Family Medicine, The Ohio State University College of Medicine, \\ Columbus, OH, USA \\ Correspondence to: Peter J. Kneuertz, MD. Thoracic Surgery Division, Department of Surgery, The Ohio State University Wexner Medical Center, \\ Doan Hall N846, 410 West 10 ${ }^{\text {th }}$ Avenue, Columbus, OH 43210, USA. Email: Peter.Kneuertz@osumc.edu.
}

Submitted Dec 20, 2019. Accepted for publication Jan 13, 2020.

doi: $10.21037 /$ jtd.2019.12.139

View this article at: http://dx.doi.org/10.21037/jtd.2019.12.139

Patient-reported outcomes (PROs) are considered an essential element in the assessment and delivery of highquality, patient-centered care (1). These measures can represent the patient's voice, providing direct feedback about healthcare experiences as well as about perceptions of treatment effects. Fortunately, the importance and of gathering PROs is recognized in healthcare policy, as evidenced in the mission of the Patient-Centered Outcomes Research Institute (PCORI) that was created through the Affordable Care Act and continues to be funded (2). Additionally, the Centers for Medicare and Medicaid Services (CMS) and the National Quality Forum (NQF) have endorsed the collection and use of PROs, and laid a pathway for PROs to be used as both performance measures and for quality improvement (2). This recognition of the importance of PROs as performance measures has spread across most areas of medicine, and is starting to increase the patient-centeredness of care provision $(3,4)$.

\section{Opportunities for PROs in thoracic surgery}

In surgery, there are clear and important opportunities for the use of PROs to improve quality of care, and specifically for patients undergoing thoracic operations. Thoracic operations have been associated with major changes in patients' health-related quality of life (hr-QOL) including physical functioning and emotional, social and mental well-being; this type of impact is paralleled by few other fields in medicine or surgery $(5,6)$. In addition, patients undergoing major thoracic surgery can experience a myriad of postoperative symptoms such as pain, fatigue, dyspnea, emotional distress, and anxiety, all of which may be ameliorated with though the development and delivery of thoughtful interventions (7). Previous studies have examined the effects of surgery on hr-QOL and postoperative symptoms, and have demonstrated that both can be impacted by the extent of surgery, as well as the surgical approach (8). Consequentially, it is our opinion, that there is need for thoracic surgery research that focuses on PROs.

Patient-reported data which reflect the quality and value of surgical care from a patient's perspective are needed to ensure best practices in care as well as to highlight opportunities for changes that are focused on improving the experience of our patients undergoing thoracic surgery. Going forward, it will be important to incorporate PROs as primary or secondary endpoints in comparative effectiveness studies and clinical trials in order to appropriately represent patients' perspectives of their care and experience. A prime example is the recent study by Bendixen and colleagues, who performed a randomized controlled patient blinded clinical trial comparing video-assisted thoracoscopic (VATS) lobectomy with the open thoracotomy approach. This trial was designed by using pain and quality of life and as the primary study endpoints. Appropriately powered to show differences in these endpoints, this trial demonstrated that VATS resulted in less postoperative pain and better quality of life than thoracotomy in the first year after the operation. 
Nonetheless, most comparative effectiveness studies incorporating PROs have been small and have had limited clinical impact. As Khullar and Fernandez point out in a recent review, the routine collection of PRO data in clinical practice is needed to provide clinicians and researchers with the needed PRO data on a large scale (5). The American College of Chest Physicians (ACCP) has long recommended that a validated hr-QOL instrument be used to evaluate all patients undergoing surgery for lung cancer (9). However, such practice is far from common, as evidenced by results of a survey of members of the European Society of Thoracic Surgeons (ESTS) which showed that over half (54\%) of surgeons had never collected quality of life data (10). In practice, collection of PROs on a large scale for routine clinical use has long been hindered by the efforts associated with the data collection process. Traditionally, surveys with PRO measures have been difficult to administer due to time constraints of both patients and providers, and have been associated with both administrative and data burdens. Fortunately, data collection processes have dramatically improved now that electronic survey methods such as questionnaires via email or web-based platforms are now widely available. These options are convenient for patients, and can save time when the survey questions can be adapted based on patients' responses; further, these approaches record data digitally making results readily available for analysis. PRO-based data collection applications (apps) have also been developed for mobile devices, with these apps accessible on patients' own smart devices. This approach has proved to be effective in engaging patients to take an active part in their perioperative care and provide feedback, as demonstrated in our study included in this focused issue (11). The American College of Surgeons and the Society of Thoracic Surgery are currently exploring how to integrate PROs into the general thoracic database, which will be essential to guide future patient centric clinical quality improvement efforts and real-world outcomes research (12).

\section{Current challenges, or more opportunities}

There remain a number of issues that affect the use of PROs in thoracic surgery. First, while there are a large variety of tools available as well as validated questionnaires, there is a lack of commonly accepted standards for PRO collection and subsequent analysis. As a result, the selected data collection approaches differ across studies, and this makes it difficult to compare outcome data from one study with data from another study (8). Second, the spectrum of PROs is wide, but the meaning of individual PROs is not always known. While every aspect of patient-reported QOL and symptoms may be considered important on a fundamental level, our understanding remains limited with respect to what really matters to patients. This limited understanding is particularly salient in the context of surgery where there are many phases of care delivery and patient experience (i.e., from the perioperative setting to long-term recovery). Third, in order for PRO information to be meaningful in the delivery of clinical care, it is important to better understand the relationships between patient-reported and traditional surgical outcomes such as complications, length of hospital stay and postoperative rehabilitation needs. One important avenue for future research will be using PROs to identify at-risk populations-such as patients who may suffer more severe symptoms, significant functional disabilities, or psychosocial problems-and select the appropriate operation or alternative treatments as well as tailor perioperative care to their identified needs.

In summary, PROs have an important role in thoracic surgery as our ultimate goal is to provide the best possible patient-centered surgical care. There are great opportunities to make an impact on our patients by collecting and using PROs for both research and improving clinical care itself. While methodological challenges still exist, addressing these challenges presents additional opportunities to advance the field.

This focused issue in Fournal of Thoracic Disease has been designed to discuss current topics about PROs in thoracic surgery. The topics have been carefully assembled and include reviews on methodological best practices, correlative opportunities relative to transitional outcomes, research opportunities in PRO data collection, and present overall broader implications and future trends for PRO collection and use in thoracic surgery.

\section{Acknowledgments}

Funding: None.

\section{Footnote}

Provenance and Peer Review: This article was commissioned by the editorial office for the series "Patient reported Outcomes in Thoracic Surgery: A new Frontier" published in Fournal of Thoracic Disease. The article did not undergo external peer review.

Conflicts of Interest: All authors have completed the ICMJE 
uniform disclosure form (available at http://dx.doi. org/10.21037/jtd.2019.12.139). The series "Patient reported Outcomes in Thoracic Surgery: A new Frontier" was commissioned by the editorial office without any funding or sponsorship. PJK served as the unpaid Guest Editor of the series. The other authors have no other conflicts of interest to declare.

Ethical Statement: The authors are accountable for all aspects of the work in ensuring that questions related to the accuracy or integrity of any part of the work are appropriately investigated and resolved.

Open Access Statement: This is an Open Access article distributed in accordance with the Creative Commons Attribution-NonCommercial-NoDerivs 4.0 International License (CC BY-NC-ND 4.0), which permits the noncommercial replication and distribution of the article with the strict proviso that no changes or edits are made and the original work is properly cited (including links to both the formal publication through the relevant DOI and the license). See: https://creativecommons.org/licenses/by-nc-nd/4.0/.

\section{References}

1. Kneuertz PJ, Moffatt-Bruce SD. Search for Meaningful Use of Patient-Reported Outcomes in Thoracic Surgery. Ann Thorac Surg 2020;109:1317-8.

2. National Quality Forum - Patient-Reported Outcomes in Performance Measurement. 2012. Available online: https:// www.qualityforum.org/Publications/2012/12/PatientReported_Outcomes_in_Performance_Measurement.aspx

3. Wu AW, Snyder C. Getting ready for patient-reported outcomes measures (PROMs) in clinical practice. Healthc Pap 2011;11:48-53; discussion 55-8.

Cite this article as: Kneuertz PJ, McAlearney AS, MoffattBruce SD. Patient-reported outcomes in thoracic surgeryopportunities and current challenges. J Thorac Dis 2020;12(11):6880-6882. doi: 10.21037/jtd.2019.12.139
4. Basch E, Spertus J, Dudley RA, et al. Methods for Developing Patient-Reported Outcome-Based Performance Measures (PRO-PMs). Value Health 2015;18:493-504.

5. Khullar OV, Fernandez FG. Patient-Reported Outcomes in Thoracic Surgery. Thorac Surg Clin 2017;27:279-90.

6. Hopkins KG, Ferson PF, Shende MR, et al. Prospective study of quality of life after lung cancer resection. Ann Transl Med 2017;5:204.

7. Fagundes CP, Shi Q, Vaporciyan AA, et al. Symptom recovery after thoracic surgery: Measuring patientreported outcomes with the MD Anderson Symptom Inventory. J Thorac Cardiovasc Surg 2015;150:613-9.e2.

8. Singer ES, Kneuertz PJ, Nishimura J, et al. Effect of Operative Approach on Quality of Life following Anatomic Lung Cancer Resection. J Thorac Dis 2020;12:6913-9.

9. Colt HG, Murgu SD, Korst RJ, et al. Follow-up and surveillance of the patient with lung cancer after curativeintent therapy: Diagnosis and management of lung cancer, 3rd ed: American College of Chest Physicians evidence-based clinical practice guidelines. Chest 2013;143:e437S-54S.

10. Pompili C, Novoa N, Balduyck B, et al. Clinical evaluation of quality of life: a survey among members of European Society of Thoracic Surgeons (ESTS). Interact Cardiovasc Thorac Surg 2015;21:415-9.

11. Kneuertz PJ, Jagadesh N, Perkins A, et al. Improving Patient Engagement, Adherence, and Satisfaction in Thoracic Surgery with Implementation of a Mobile Device Platform for Patient Reported Outcomes. J Thorac Dis 2020;12:6883-91.

12. Khullar OV, Rajaei MH, Force SD, et al. Pilot Study to Integrate Patient Reported Outcomes After Lung Cancer Operations Into The Society of Thoracic Surgeons Database. Ann Thorac Surg 2017;104:245-53. 